\title{
Intensivmedisinsk behandling av barn
}

\author{
Sammendrag \\ Bakgrunn. Barns fysiologi og sykdoms- \\ panorama er forskjellig fra voksnes, \\ og dette medfører forskjeller i intensiv- \\ medisinske problemstillinger. Formå- \\ let med denne oversiktsartikkelen er \\ å belyse spesielle diagnostiske og tera- \\ peutiske problemstillinger innen pedia- \\ trisk intensivmedisin.
}

Materiale og metode. Oversikten er basert på ikke-systematiske litteratursøk i PubMed, samt forfatternes egne erfaringer.

Resultater. Vanlige årsaker til intensivinnleggelser hos barn er hodeskader, septisk sjokk og respirasjonssvikt. Den perfusjonsorienterte behandling av traumatiske hodeskader er anerkjent, men optimale aldersavhengige grenseverdier for blodtrykk og intrakranialt trykk er ufullstendig studert. Terapeutisk hypotermi ved hodeskader er kontroversielt. Ved septisk sjokk er lavt hjerteminuttvolum typisk, dermed er dopamin og adrenalin best egnet som farmakologisk sirkulasjonsstøtte, dette i motsetning til hos voksne der dominerende vasoplegi gjør noradrenalin til førstevalg. Aktivert protein $\mathrm{C}$ har ingen plass i behandling av septisk sjokk hos barn. Ikke-invasiv ventilasjonsstøtte anvendes $\mathrm{i} ø$ kende omfang hos barn med respirasjonssvikt. Forfatternes erfaringer tilsier at dette reduserer behov for intubering, men det er ikke dokumentert i studier. Toleranseutvikling og abstinens ved bruk av sedativer og analgetika er et betydelig klinisk problem ved intensivbehandling av barn, og relateres til totaldose og varighet av infusjoner.

Fortolkning. Intensivbehandling av barn skiller seg fra intensivbehandling av voksne. Behandlingen er i mindre grad forankret i gode studier og i større grad erfaringsbasert.

\section{Ulf Mostad}

ulf.mostad@stolav.no

Sigurd Fasting

Klinikk for anestesi og akuttmedisin

St. Olavs hospital

7006 Trondheim

Basert på amerikanske og australske estimater skulle man forvente at 1400 barn i alderen fra fire uker til 18 år innlegges i norske intensivavdelinger årlig (1). Ifølge Norsk intensivregister (NIR) var det i 2006 knapt 900 pasienter under 20 år som ble intensivbehandlet, nyfødte er holdt utenfor. Dette tallet synes lavt og kan skyldes underapportering, eller forskjeller i klassifisering av intensivpasienter.

Barns fysiologi og sykdomspanorama er forskjellig fra voksnes, og det medfører forskjeller i de intensivmedisinske problemstillingene. Barn med kroniske sykdommer og medfødte misdannelser er overrepresentert, ofte som følge av interkurrent sykdom eller kirurgiske inngrep. Det foreligger få studier fra pediatrisk intensivmedisin, og ofte med små pasientpopulasjoner. Man må dermed $\mathrm{i}$ stor grad støtte seg til erfaringskunnskap og vitenskapelige arbeider fra andre aldersgrupper.

Her gjennomgås behandlingsresultater fra pediatrisk intensivmedisin, og det blir lagt vekt på noen tilstander og problemområder der vurderingene ved behandling av barn skiller seg fra behandling av voksne.

\section{Materiale og metode}

Grunnlaget for artikkelen er ikke-systematiske litteratursøk i PubMed. Artiklene er vurdert ut fra forfatternes skjønn og på grunnlag av erfaring innen fagområdet.

\section{Behandlingsresultater}

Totalmortaliteten ved intensivbehandling av barn er rundt $5 \%$. For sepsis er dødeligheten mindre enn $10 \%$. Dette er lavere enn mortaliteten hos voksne. I et australsk materiale på 432 intensivbehandlede barn, levde $92 \%$ tilnærmet et normalt og uavhengig liv ved evaluering 3-24 måneder etter utskrivning. $2 \%$ var pleietrengende og $6 \%$ døde (2).

\section{Hodeskader}

Ved alvorlige hodeskader er rask transport til sykehus med nevrokirurgisk kompetanse viktig. Behandling av traumatiske hodeskader retter seg mot begrensning av sekundære skader som skyldes hypoksi og iskemi. Hos barn har hodeskader ofte vært håndtert $i$ henhold til behandlingsalgoritmer for voksne, selv om dokumentasjonen har manglet.

Den perfusjonsorienterte hodeskadebehandling har gyldighet for barn, men med aldersjusterte grenseverdier for blodtrykk og intrakranialt trykk (tab 1). Hvilke verdier som kan anses optimale, er imidlertid ikke entydig (3).

Hyperosmolær terapi med mannitol har lang tradisjon, men er lite studert hos barn. Effekten av hypertont saltvann til barn er dokumentert i flere studier (4). Veiledende dosering til barn er vist i tabell 2 .

Hypotermi ved hodeskader er anbefalt hos voksne. I en fersk multisenterstudie ble 225 barn randomisert til enten 24 timer hypotermi $\left(32,5^{\circ} \mathrm{C}\right)$ med start innen åtte timer etter hodeskaden eller normotermi $\left(37^{\circ} \mathrm{C}\right)$ (5). I hypotermigruppen var mortaliteten høyere (21 \% mot $12 \%)$, og flere hadde dårlig nevrologisk funksjonsnivå ved evaluering etter seks måneder ( $31 \%$ mot $22 \%)$. Hypertont saltvann ble gitt hyppigere mot høyt intrakranialt trykk i normotermigruppen. Det var flere hypotensive episoder i hypotermigruppen og mer behov for vasoaktive medikamenter i oppvarmingsfasen. Studien ga ikke grunnlag for å anbefale hypotermi ved hodeskader hos barn, men det er mulig at tidligere start og lengre varighet av hypotermi kan ha positiv effekt (5).

Dekomprimerende kraniektomi har gitt gode resultater som tidlig intervensjon ved refraktær intrakranial hypertensjon etter hodeskader (6). Internasjonale retningslinjer for behandling av traumatiske hjerneskader hos barn ble publisert i 2003 (3).

\section{Hovedbudskap}

- Terapeutisk hypotermi er ikke vist å ha positiv effekt ved traumatiske hodeskader med forhøyet intrakranialt trykk

- Septisk sjokk med lavt hjerteminuttvolum responderer ofte ikke på væske eller dopamin

- Ikke-invasiv ventilasjonsstøtte kan muligens redusere behovet for intubering og respiratorbehandling

- Klonidin er fordelaktig ved toleranseutvikling og abstinens i relasjon til intensivsedasjon 


\section{Septisk sjokk}

Hjertefrekvens, kapillarfylling og bevissthetsnivå er gode indikatorer på sirkulasjonsstatus hos barn. Blodtrykksfall opptrer sent og varsler truende sirkulasjonskollaps.

Foruten antibiotika er sirkulasjonsstøtte vesentlig for overlevelse ved sepsis. Hos voksne er vasoplegi med lav perifer karmotstand et dominerende trekk, såkalt «varmt» sjokk. Hos barn er imidlertid myokardsvikt med lavt hjerteminuttvolum vanligere, og kombinert med enten hyppigst høy eller sjeldnere lav perifer karmotstand.

Hypovolemi korrigeres primært med isoton krystalloid eller kolloid væske som gjentatte infusjonsstøt på $20 \mathrm{ml} / \mathrm{kg}$, inntil totalt $60 \mathrm{ml} / \mathrm{kg}$ eller mer.

Dersom væske ikke stabiliserer sirkulasjonen, vil dopamin være førstevalg som inotropi. Dopaminresistens er imidlertid vanlig ved septisk sjokk hos barn. I så fall gis adrenalin eller dobutamin om det er «kaldt» sjokk med lavt hjerteminuttvolum. Ved «varmt» sjokk er en ren vasopressor som noradrenalin aktuell. Bruk av vasopressin er foreløpig ikke dokumentert hos barn.

I forløpet kan det være aktuelt å legge til en vasodilator som nitroprussid for å lette hjertets arbeidsbelastning. Milrinon og levosimendan er nyere preparater med kombinerte inotrope og vasodilaterende egenskaper, men dokumentasjonen begrenser seg til kasuistiske serier $(7,8)$. Farmakologisk sirkulasjonsstøtte er ellers omtalt i tabell 3 (9).

Ved manglende effekt av katekolaminer, kan det $\mathrm{i}$ halvparten av sepsistilfellene påvises relativ binyrebarksvikt, men lavdosert hydrokortison som substitusjonsbehandling er verken vist å redusere behovet for vasoaktive medikamenter eller å bedre overlevelsen hos barn (10).

Blodsukkerkontroll hos voksne sepsispasienter er omdiskutert. Hos barn er dette knapt studert. I et materiale med 942 intensivbehandlede barn ble det funnet både høyere mortalitet $(6,1 \%$ mot $1,5 \%)$ og lengre liggetid ( 6,1 mot 4,0 dager) blant barn beroende på om høyest målte glukoseverdi var over eller under $8,5 \mathrm{mmol} / 1$ (11). Et minstekrav må være at blodsukkerverdiene gjennomgående holdes under $10 \mathrm{mmol} / \mathrm{l}$ (12).

Aktivert protein $\mathrm{C}$ (drotrecogin alfa) er vurdert i RESOLVE-studien som inkluderte 477 barn med septisk sjokk. Det ble ikke funnet bedret overlevelse sammenliknet med placebo. Blødninger i sentralnervesys-
Tabell 1 Vanlig brukte aldersavhengige grenseverdier for intrakranialt trykk og perfusjonstrykk ved intensivbehandling av traumatiske hjerneskader (3). Hjernens perfusjonstrykk er lik middel arterietrykk minus intrakranialt trykk målt i mm Hg

\begin{tabular}{lccccc} 
& \multicolumn{5}{c}{ Alder (år) } \\
& $0-1$ & $1-2$ & $2-6$ & $6-12$ & $>12$ \\
\hline Intrakranialt trykk & 15 & 20 & 20 & 20 & 20 \\
Perfusjonstrykk & 45 & 45 & 50 & 55 & 60
\end{tabular}

Tabell 2 Hyperosmolær terapi til barn ved traumatiske hodeskader med forhøyet intrakranialt trykk. Veiledende infusjonsdosering for mannitol og hypertont saltvann, adaptert fra (3)

\begin{tabular}{|c|c|c|c|}
\hline & Bolusdose & Videre dosering & Forutsatt s-osmolalitet \\
\hline Mannitol & $0,5-1 \mathrm{~g} / \mathrm{kg}$ & $\begin{array}{c}0,25-0,5 \mathrm{~g} / \mathrm{kg} \\
\text { (gjentatt bolus) }\end{array}$ & $<320 \mathrm{mosm} / \mathrm{kg}$ \\
\hline Natriumklorid & $1-2,5 \mathrm{mmol} / \mathrm{kg}$ & $0,05-0,5 \mathrm{mmol} / \mathrm{kg} / \mathrm{t}$ & $<360 \mathrm{mosm} / \mathrm{kg}$ \\
\hline
\end{tabular}

Tabell 3 Farmakologisk sirkulasjonsstøtte ved septisk sjokk hos barn når initial væsketerapi og dopamin ikke har gitt tilfredsstillende respons (9)

\begin{tabular}{lll} 
& Primært & Eventuelt tillegg \\
$\begin{array}{l}\text { Høyt hjerteminuttvolum og lav } \\
\text { perifer karmotstand }\end{array}$ & $\begin{array}{l}\text { Vasopressor } \\
\text { Noradrenalin }\end{array}$ & $\begin{array}{l}\text { Vasopressor } \\
\text { (Vasopressin) }\end{array}$ \\
$\begin{array}{l}\text { Lavt hjerteminuttvolum og høy } \\
\text { perifer karmotstand }\end{array}$ & $\begin{array}{l}\text { Inotropi } \\
\text { Adrenalin }\end{array}$ & $\begin{array}{l}\text { Vasodilatasjon, ev. + inotropi } \\
\text { Nitroprussid } \\
\text { Dobutamin } \\
\text { Milrinon }\end{array}$ \\
& & Levosimendan \\
\hline $\begin{array}{l}\text { Lavt hjerteminuttvolum og lav } \\
\text { perifer karmotstand }\end{array}$ & Inotropi & $\begin{array}{l}\text { Vasopressor } \\
\text { Noradrenalin } \\
\end{array}$ \\
& Adrenalin & (Vasopressin)
\end{tabular}

temet forekom hyppigere hos små barn i behandlingsgruppen, og konklusjonen må være at bruk til barn frarådes (13).

Akutt nyresvikt som ledd i flerorganpåvirkning er vanlig ved septisk sjokk, men resulterer sjelden i dialysebehov hos barn. Siste utgave av internasjonale retningslinjer fra Surviving Sepsis Campaign, har et eget kapittel som omhandler barn (9).

\section{Respirasjonssvikt}

Ikke-invasiv ventilasjonsstøtte har fått økende innpass, og vår erfaring tyder på at dette kan innebære redusert behov for intubering og respiratorbehandling, men det foreligger få studier av dette (14).

Ved konvensjonell respiratorbehandling er lungeprotektiv ventilasjonsstrategi etablert praksis. Dette betyr begrensning av respiratorens topptrykk og tidevolumer der man som konsekvens aksepterer $\mathrm{CO}_{2}$-nivåer over normalområdet. For å motvirke atelektaser anvendes høyt positivt endeekspiratorisk trykk. Man støtter seg her i stor grad på studier som gjelder voksne pasienter med akutt lungesviktsyndrom.

For å oppnå bedre oksygenering, har vi i flere tilfeller anvendt mageleie, men $i$ en amerikansk studie som inkluderte 102 barn, kunne man ikke påvise noen effekt, verken på respiratortid eller dødelighet, sammenliknet med ryggleie (15).

Høyfrekvent oscillerende ventilasjon (HFOV) er et alternativ til konvensjonell respiratorbehandling ved alvorlig oksygeneringssvikt, men synes i dag lite brukt utover nyfødtalder.

Inhalert nitrogenmonoksid (iNO) gir bedret oksygenering gjennom optimalisering av lungenes ventilasjon-perfusjons-forhold, i

Tabell 4 Veiledende dosering for aktuelle medikamenter til sedering av barn som respiratorbehandles

\begin{tabular}{lll} 
& Bolusdose & Vedlikeholdsinfusjon \\
\hline Midazolam & $0,1-0,2 \mathrm{mg} / \mathrm{kg}$ & $0,1-0,3 \mathrm{mg} / \mathrm{kg} /$ time (eller mer) \\
\hline Morfin & $0,05-0,1 \mathrm{mg} / \mathrm{kg}$ & $0,025-0,1 \mathrm{mg} / \mathrm{kg} /$ time (eller mer) \\
\hline Fentanyl & $1-2 \mu \mathrm{g} / \mathrm{kg}$ & $1-4(-10) \mu \mathrm{g} / \mathrm{kg} / \mathrm{time}$ \\
\hline Klonidin & Ev. $0,5-1 \mu \mathrm{g} / \mathrm{kg}$ & $0,5-2 \mu \mathrm{g} / \mathrm{kg} / \mathrm{time}$
\end{tabular}


alle fall initialt. Det er ikke vist effekt på respiratortid eller mortalitet.

Surfaktantbehandling ved lungesvikt har vært forsøkt hos eldre barn og voksne. I en randomisert, kontrollert studie som inkluderte 153 barn, ble det funnet både bedret oksygenering og lavere mortalitet, $19 \%$ for modifisert kalvesurfaktant, mot $36 \%$ for placebo, men uten forskjell i respiratortid (16).

Tre ulike strategier for respiratoravvenning ble sammenliknet i en amerikansk studie med 182 pasienter. To var protokoller for henholdsvis trykkstøtte og volumstøtte, og en var basert på klinisk skjønn, altså ikkeprotokoll. Det var ingen signifikante forskjeller mellom gruppene hva angikk tid til ekstubering eller forekomst av reintubering. Tid til ekstubering var mindre enn to døgn for alle gruppene. Ellers fremgikk det av materialet at totalmortalitet var $1,6 \%$, mens den ved akutt lungesviktsyndrom var $4,3 \%$. Median respiratortid var seks dager ved pneumoni, sju dager ved bronkiolitt og 11 dager ved akutt lungesviktsyndrom. Respiratortid på mer enn 28 dager forekom sjelden $(17,18)$. Reintubasjon forekom hos $6,2 \%$ i en studie på 2794 respiratorbehandlede barn. Risikofaktorer for mislykket ekstubering var alder under to år, ledsagende kronisk sykdom og lang respiratortid. $\mathrm{Pa}-$ sientgruppen som trengte reintubering hadde høyere mortalitet (19).

Stort væskeoverskudd er verken vist å forsinke respiratoravvenning eller å gi økt reintuberingsrate (20). Systemiske steroider og inhalert racemisk adrenalin kan bidra til å redusere frekvensen av mislykket ekstubering. Endotrakealtuber med ballong (cuff) forårsaker ikke flere komplikasjoner enn tuber uten ballong hos respiratorbehandlede barn (21). Trakeostomi utføres sjelden på barn. Vanligste årsaker er obstruktive prosesser i luftveiene, kronisk lungesykdom, manglende protektive reflekser, nevromuskulær svikt eller sentral hypoventilasjon (22). Ekstrakorporal membranoksygenering (ECMO) ved akutt livstruende lungesvikt er avansert intensivterapi med gode resultater i flere studier. Det forutsetter normalt et spesialisert team fra mottakende sykehus som rykker ut og starter behandling før transport (23). Rikshospitalet må kontaktes tidlig om det foreligger progredierende og alvorlig lungesvikt uten respons på konvensjonell behandling (24). Ekstrakorporal membranoksygenering kan også gi sirkulasjonsstøtte, eventuelt kombinert med hemofiltrasjon eller dialyse, og er vist å være effektivt ved septisk sjokk (25).

\section{Sedering ved respiratorbehandling}

Det er kjent at toleranseutvikling og abstinens kan være et stort problem hos barn. Mekanismen for dette er ikke klarlagt, det kan være betinget i farmakodynamiske forhold, som modulering på reseptornivå eller intracellulært. Metabolisme og utskilling er vanligvis upåvirket, og toleransen har dermed ingen farmakokinetisk årsak.

En kartlegging av 20 britiske barneintensivavdelinger i 2007 viste at sederingspraksisen var svært heterogen, med 24 ulike sedativer og analgetika i bruk. Midazolam og morfin var de vanligst brukte preparatene til sedering av barn som ble respiratorbehandlet, men hele $39 \%$ fikk 12 eller flere ulike sedativer og analgetika. Abstinensutvikling var assosiert med større totaldose og lengre varighet av infusjon med midazolam og morfin. Hele $78 \%$ av abstinenstilfellene debuterte innen en uke etter innleggelse, mens median tid var fem døgn. Tiden fra nedtrapping startet til abstinenssymptomer debuterte, var under 12 timer hos $48 \%$. Hos noen få debuterte disse symptomene med mer enn 48 timers forsinkelse. Bare $13 \%$ av de respiratorbehandlede utviklet symptomer på abstinens, men median tid for intensivoppholdene var heller ikke mer enn fire døgn (26). $\alpha_{2}$-agonisten klonidin er de siste årene stadig mer anvendt både til sedasjon og til abstinensbehandling. Vanlige bivirkninger er bradykardi og hypotensjon (27).

Med bakgrunn i det mye omtalte propofolinfusjonssyndromet (PRIS) med utvikling av metabolsk acidose og flerorgansvikt, brukes propofol knapt til kontinuerlig sedering i dag. Det er på verdensbasis frem til 2006 rapportert til sammen 48 tilfeller av propofolinfusjonssyndrom, hvorav 28 barn (28). Store doser over lang tid øker risikoen. Den britiske praksiskartleggingen viste at bare $2,6 \%$ av respiratorbehandlede barn hadde fått propofol; alle var i alderen 4-13 år, infusjonene oversteg ikke $2 \mathrm{mg} / \mathrm{kg} / \mathrm{time} \mathrm{i}$ noe tilfelle og median varighet var 48 timer (26). Vi har i en viss utstrekning brukt propofol under nedtrapping av andre sedativer, og i påvente av ekstubering hos intensivbarn i ellers stabil tilstand. Propofol har da vært gitt i doser på inntil $2 \mathrm{mg} / \mathrm{kg} /$ time og med en varighet av under ett døgn. Anestesigass har $i$ et visst omfang vært brukt som sedasjon under respiratorbehandling. Isofluran er best studert (29). Nevromuskulære blokkere bør ikke brukes til andre pasienter enn de med kritisk oksygeneringssvikt eller forhøyet intrakranialt trykk. Den britiske kartleggingen påviste bruk av nevromuskulære blokkere hos $30 \%$ av alle respiratorbehandlede barn. I alt ble fire ulike nevromuskulære blokkere anvendt (26).

Nevromyopati etter kritisk sykdom og sepsis er beskrevet hos barn i flere rapporter, men forekommer trolig sjeldnere enn hos voksne (30). Britiske retningslinjer for sedasjon og analgesi til kritisk syke barn ble publisert i 2006, og for bruk av nevromuskulære blokkere i $2007(31,32)$. Dosering av intensivsedasjon vises i tabell 4 .

\section{Oppgitte interessekonflikter: Ingen}

\section{Litteratur}

. Shann F. Paediatric intensive care. Lancet 1993; 342: 1240.

2. Morrison AL, Gillis J, O'Connell AJ et al. Quality of life of survivors of pediatric intensive care. Pediatr Crit Care Med 2002; 3: 1-5.

3. Society of Critical Care Medicine. Guidelines for the acute medical management of severe traumatic brain injury in infants, children, and adolescents. Crit Care Med 2003; 31 (suppl): 407-91.

4. Khanna S, Davis D, Peterson B et al. Use of hyper tonic saline in the treatment of severe refractory posttraumatic intracranial hypertension in pediatric traumatic brain injury. Crit Care Med 2000: 28: $1144-51$

5. Hutchison JS, Ward RE, Lacroix J et al; Hypothermia Pediatric Head Injury Trial Investigators and the Canadian Critical Care Trials Group. Hypothermia therapy after traumatic brain injury in children. N Engl J Med 2008; 358: 2447-56.

6. Taylor A, Butt W, Rosenfeld J et al. A randomized trial of very early decompressive craniectomy in children with traumatic brain injury and sustained intracranial hypertension. Childs Nerv Syst 2001; 17: $154-62$

7. Carcillo JA, Fields Al; American College of Critical Care Medicine Task Force Committee Members. Clinical practice parameters for hemodynamic support of pediatric and neonatal patients in septic shock. Crit Care Med 2002; 30: 1365-78.

8. Carcillo JA. What's new in pediatric intensive care. Crit Care Med 2006; 34 (suppl): 183-90.

9. Dellinger RP, Levy MM, Carlet JM et al; International Surviving Sepsis Campaign Guidelines Committee. Surviving Sepsis Campaign: international guidelines for management of severe sepsis and septic shock: 2008. Crit Care Med 2008; 36 . and septic

10. Zimmerman JJ. A history of adjunctive glucocorticoid treatment for pediatric sepsis: moving beyond steroid pulp fiction toward evidence-based medicine. Pediatr Crit Care Med 2007; 8: 530-9

11. Branco RG, Garcia PC, Piva JP et al. Glucose level and risk of mortality in pediatric septic shock. Pediatr Crit Care Med 2005; 6: 470-2.

12. Faustino EV, Apkon M. Persistent hyperglycemia in critically ill children. J Pediatr 2005; 146: 30-4

13. Nadel S, Goldstein B, Williams MD et al; REsearch ing severe Sepsis and Organ dysfunction in children: a gLobal perspective (RESOLVE) study group. Drotrecogin alfa (activated) in children with severe sepsis: a multicentre phase III randomised controlled trial. Lancet 2007; 369: 836-43

14. Essouri S, Chevret L, Durand P et al. Noninvasive positive pressure ventilation: five years of experience in a pediatric intensive care unit. Pediatr Crit Care Med 2006; 7: 329-34

15. Curley MA, Hibberd PL, Fineman LD et al. Effect of prone positioning on clinical outcomes in children with acute lung injury: a randomized controlled trial. JAMA 2005; 294: 229-37.

16. Willson DF, Thomas NJ, Markovitz BP et al; Pediatric Acute Lung Injury and Sepsis Investigators. Effect of exogenous surfactant (calfactant) in pediatric acute lung injury: a randomized controlled trial. JAMA 2005; 293: 470-6.

17. Randolph AG, Wypij D, Venkataraman ST et al; Pediatric Acute Lung Injury and Sepsis Investigators (PALISI) Network. Effect of mechanical ventilator weaning protocols on respiratory outcomes in infants and children: a randomized controlled trial. JAMA 2002; 288: 2561-8.

18. Randolph AG, Meert KL, O'Neil ME et al: Pediatric Acute Lung Injury and Sepsis Investigators Network. The feasibility of conducting clinical trials in infants and children with acute respiratory failure. Am J Respir Crit Care Med 2003; 167: 1334-40.

19. Kurachek SC, Newth CJ, Quasney MW et al. Extubation failure in pediatric intensive care: a multiple-center study of risk factors and outcomes. Crit Care Med 2003; 31: 2657-64

20. Randolph AG, Forbes PW, Gedeit RG et al: Pediatric Acute Lung Injury \& Sepsis Investigators (PALISI) Network. Cumulative fluid intake minus output is not associated with ventilator weaning duration or extubation outcomes in children. Pediatr Crit Care Med 2005; 6: 642-7. 
21. Newth CJ, Rachman B, Patel $N$ et al. The use of cuffed versus uncuffed endotracheal tubes in pediatric intensive care. J Pediatr 2004; 144: 333-7.

22. Graf JM, Montagnino BA, Hueckel R et al. Pediatric tracheostomies: a recent experience from one academic center. Pediatr Crit Care Med 2008; 9 : 96- 100.

23. Bartlett RH, Roloff DW, Custer JR et al. Extracorporeal life support: the University of Michigan experience. JAMA 2000; 283: 904-8

24. Rikshospitalet. Håndbok for ECMO 2006. www.rikshospitalet.no/iKnowBase/Content/ 413740/1903_ecmo_norsk.doc (9.7.2008).

25. Maclaren G, Butt W, Best D et al. Extracorporeal membrane oxygenation for refractory septic shock in children: one institution's experience. Pediatr Crit Care Med 2007; 8: 447-51.

26. Jenkins IA, Playfor SD, Bevan C et al. Current United Kingdom sedation practice in pediatric intensive care. Paediatr Anaesth 2007; 17: 675-83.

27. Ambrose C, Sale S, Howells R et al. Intravenous clonidine infusion in critically ill children: dosedependent sedative effects and cardiovascular stability. Br J Anaesth 2000; 84: 794-6.

28. Fudickar A, Bein B, Tonner PH. Propofol infusion syndrome in anaesthesia and intensive care medicine. Curr Opin Anaesthesiol 2006; 19: 404-10.

29. Tobias JD. Therapeutic applications and uses of inhalational anesthesia in the pediatric intensive care unit. Pediatr Crit Care Med 2008; 9: 169-79.

30. Williams S, Horrocks IA, Ouvrier RA et al. Critical illness polyneuropathy and myopathy in pediatric intensive care: a review. Pediatr Crit Care Med 2007; 8: 18-22.

31. Playfor S, Jenkins I, Boyles C et al; United Kingdom Paediatric Intensive Care Society Sedation; Analgesia and Neuromuscular Blockade Working Group. Consensus guidelines on sedation and analgesia in critically ill children. Intensive Care Med 2006; 32: 1125-36.

32. Playfor S, Jenkins I, Boyles $C$ et al; United Kingdom Paediatric Intensive Care Society Sedation, Analgesia and Neuromuscular Blockade Working Group. Consensus guidelines for sustained neuromuscular blockade in critically ill children. Paediatr Anaesth 2007; 17: $881-7$

Manuskriptet ble mottatt 9.7. 2008 og godkjent 8.1. 2009. Medisinsk redaktør Are Brean. 